\title{
Relationship between Staff Morale and Intention to Leave among Professional Nurses at Damanhour National Medical Institute
}

\author{
Mayada Hassan Saad Elzohairy; Prof. Dr. Neamate Mohamed Elsayed; \\ Prof. Dr. Sanaa Abd- Elazim Ibrahim
}

MSc, Faculty of Nursing, Alexandria University; Prof. of Nursing Administration, Faculty of Nursing, Damanhur University; Prof. of Nursing Administration, Faculty of Nursing, Port Said University

\begin{abstract}
Background: A loss of morale leads to a lack of nurse commitment to the organization, which contributes to nurse turnover. Aim: To determine the relationship between staff morale and intention to leave. Designe: A descriptive correlational design was applied in this study. Setting: The study was conducted in all the units at Damanhour National Medical Institute. Sample: Study sample was 101 professional nurses. Tools: Two tools were used for data collection; staff morale survey and intention to leave scale. Results: The results of the present study showed that above one half of professional nurses $(51.4 \%)$ had moderate level of staff morale, whereas above one third of them (30.7\%) had low level of staff morale and above half of professional nurses (52.5\%) had moderate level of intention to leave. Conclusion: The present study concluded that there was significant negative correlation between intention to leave and personal perception of staff morale. While, there was positive significant correlation between intention to leave and negative factors affecting staff morale. Recommendations: Therefore, it is recommended that, healthcare organization administrators should conduct frequent meetings with professional nurses who are dissatisfied from their job; discuss their problems and their needs and try to formulate plans to overcome these problems to enhance their satisfaction level which can consequently raise their morale and commitment level and decrease level of intention to leave.
\end{abstract}

Keywords: Staff morale, intention to leave, professional nurses. 


\section{INTRODUCTION}

Staff morale is a workforce phenomenon that confronts every organization at some time. The understanding of morale is important because it can have tangible and wide ranging effects and outcomes for an organization. Morale is not a simple concept and the outcomes associated with high or low morale may impact upon staff turnover, attainment of organizational or personal goals, the ability to adopt new practices, learning new skills and the delivery of good customer service (Mapesa, 2014). Staff Morale is defined as "the attitude of a person related to confidence, cheerfulness, discipline, and performance" (Behm, 2009). Positive morale is important in any organization because it affects employees' satisfaction, motivation, and ability to perform (Behm, 2009; Denka, 2009; Long \& Spurlock, 2008).

A loss of morale leads to a lack of nurse commitment to the organization, which contributes to nurse turnover (Harrison, Lambiase, \& Zhao, 2010). The effectiveness of an organization is related to the morale of its employees (Denka, 2009; McKenna et al., 2011). Employee turnover is expensive for the organization and negatively affects morale (Behm, 2009). Low morale financially affects hospitals and increases the risk of nurse turnover (Cottingham, DiBartolo, Battistoni, \& Brown, 2011; Unruh, 2008) and costs including recruitment and training, and loss of productivity and knowledge, reaching (Flinkman, Leino-Kilpi, \& Salantera, 2010; Jones, 2008).

A number of the writings concentrate on poor morale of health care workers and highlight a range of causes including: shortage of workers; overwork; low pay and difficulties with the recruitment and retention of staff; the quality of nursing education; professional support and prospects; and the lack of recognition for job performance and professional achievement. The way a person responds or reacts to work and organizational stimuli have a strong bearing on their subsequent perception of morale within the workplace.

Morale of nurses can be divided into two main categories namely intrinsic and extrinsic factors as well as a number of key themes. Intrinsic factors are those variables that impact upon nurses' concept of personal or professional standing within the group. It could also be argued that nurses have some control over intrinsic factors that impact upon their level of morale. Extrinsic factors take into account those variables that are controlled by the organization or other external forces. These factors are largely out of the control of the individual nurse or the group they work in. Organizational factors such as staffing, communication, training and development and 
management styles have all been cited in the organizational variables affecting the level of staff morale among health care workers (Day, Minichiello, \& Madison, 2006).

By exploring both intrinsic and extrinsic factors of morale, the factors that enhance morale appear to be intrinsic factors (giving good patient care, good relationships with co-workers, feeling respected and valued), whereas the extrinsic factors dominate the factors that reduce morale (excessive workload, fears about job security, moving to trust status). Research has demonstrated that organizational strengths were in line with intrinsic factors (desire to help others, interesting work), while concerns were focused on extrinsic factors (pay, workload, management approach) (Day, Minichiello, \& Madison, 2006).

Retention of hospital staff is important for the safety and wellbeing of patients. Studies have shown nurse-to-patient ratios are important variables influencing patient outcomes (Aiken, 2010; Christmas, 2008). The cost of replacing and training a new nurse is equal to a nurse's salary (Jones, 2008). Indirect costs of nurse turnover are significant and include decreased productivity and organizational inefficiencies (Jones, 2008; Kocakülâh, Wiggins, \& Albin, 2009). The combined effects of the initial decline of productivity because of training a new employee decrease in staff morale, and decreased group productivity cost a hospital billions of dollars (Jones, 2008). As patient acuity worsens and higher rates of poor patient outcomes occur, hospitals need to focus on retention and training nurse managers (Brennan \& Daly, 2009; Jones, 2008).

Ellenbecker (2004) define intention to leave as define intention to leave as: "A nurse's perception of the possibility of leaving or staying in the present job”. And finally, Takase (2010) define intention to leave as: "a multi-stage process involving the voluntary departure of employees from their current position, and is triggered by negative psychological responses to internal/external job context". Intention to leave has also been referred to turnover intention (Chaaban, 2006)

\section{Significance of the Study:}

Several issues negatively affect morale: conflict between administration and nursing, ineffective communication, absenteeism, retention and recruitment, staff turnover, and health risks (Douglas, 2010; Parker, Giles \& Higgins, 2009). Poor morale leads to extra costs to an organization, and affects patient care (Swiadek, 2009; Unruh, 2008). 


\section{AIM OF THE STUDY:}

Determine the relationship between staff morale and intention to leave among professional nurses at Damanhour National Medical Institute.

\section{The research questions:}

1. What is the staff morale level among professional nurses?

2. Are professional nurses had intention to leave?

3. Is there a relationship between staff morale and intention to leave?

\section{SUBJECTS AND METHOD:}

A descriptive correlational design was used in this study.

\section{Setting:}

The study was conducted in all the units at Damanhour National Medical Institute. It is one of nine hospitals belonging to the General Organization for Teaching Hospitals and Institutes- all over Egypt. The hospital is totally equipped with 541 beds. With total number of units (40 units).

\section{Subjects:}

All professional nurses worked at the fore mentioned settings, who have at least one year of experience, almost ( $\mathrm{N}=101$ professional nurse).

\section{Tools:}

Two tools were used to conduct this study:

\section{Tool 1: Staff morale survey (SMS):}

The Staff Morale Survey was initially developed for educators, but has been adapted to certified nursing assistant by Weeb, 2003. It includes a list of items in which professional nurses are to respond as to how they relate to them and how they affect staff morale in the workplace. There are three sections with a combined total of 37 items plus three openended questions. The first section addresses the professional nurse's perception of staff morale (15 items). The second section identifies negative factors affecting the morale of staff (12 items). The final section identifies positive factors that affect staff morale (13 items). Responses were measured on a 4-point Likert-type scale for all items and were measured the response categories in terms of agreement, ranging from (1) strongly disagree to (4) strongly agree. The average score for each professional nurse was converted to a percent by multiplying professional nurse score in $100 \%$ and then divided on maximum score. Overall scores were divided into categories according 
to cut off point as follows: low scores $=<33 \%$; moderate scores $=33 \%<66 \%$, and finally high scores $=66 \%-100 \%$.

\section{Tool 2: Intention to leave scale:}

Intention to leave scale was developed by Kim, Price, Mueller \& Watson (1996) to measure nurses' turnover intention. It consists of 5 items and responses were measured by a 4 point Likert-type scale for all items and were measured the response categories in terms of agreement, ranging from (1) strongly disagree to (5) strongly agree. The average score for each professional nurse was converted to a percent by multiplying professional nurse score in $100 \%$ and then divided on maximum score. Overall scores were divided into categories according to cut off point as follows: low scores $=<33 \%$; moderate scores $=33 \%<66 \%$, and finally high scores $=66 \%-100 \%$.

\section{OPERATIONAL DESIGN:}

\section{Content of validity:}

The four tools were translated into Arabic by researcher and back translated by English expert; and was tested by seven experts from Nursing Administration Departments from different Nursing Faculties for their face and content validity. Accordingly, the necessary modifications were done.

\section{Reliability:}

Tools reliability was measured using Cronbach's alpha coefficient test. The tools were reliable and the test values were as the following:

\begin{tabular}{|c|c|c|}
\hline \multicolumn{1}{|c|}{ Tool } & N of items & Test values \\
\hline Tool (1) & 37 & 0.798 \\
\hline Tool (2) & 5 & 0.836 \\
\hline
\end{tabular}

\section{Pilot study:}

A pilot study for the questionnaires was carried out on $(10 \%)$ of total sample $(n=10)$ in order to check and ensure the clarity of the questionnaires, identify obstacles and problems that may be encountered during data collection. Based on the findings of the pilot study, no modifications were done. 


\section{Field of the work:}

Data were collected by the researcher from the professional nurses through individualized schedule interviews at their work setting, concerning:

1) Staff morale survey (SMS); and

2) Intention to leave scale.

Every professional nurse took from 30 to 45 minutes to explain the aim of the study and the needed instructions were given in their work settings. Data were collected from four to five professional daily on two or three days per week in a period of four months, starting from $18^{\text {th }}$ of February 2016 to $20^{\text {th }}$ of June 2016.

\section{ADMINISTRATION DESIGN}

\section{Ethical consideration:}

Ethical consideration was considered all over the study phases and done through:-

1. Directed letters from dean of Port Said faculty of nursing to medical and nursing directors exploring the aim of the study, and taken written consent to conduct the present study.

2. An official permission was obtained from the hospital administrators to collect the necessary data.

3. Oral consent was obtained from the subjects of the study for collecting needed data after exploring the aim of the study.

4. Confidentiality and privacy was maintained.

\section{STATISTICAL DESIGN}

The SPSS V 20.0 was used for the analysis of the data. Frequency tables and cross tabulations with percentages were used to illustrate the results of categorical data and tested by the Chi Square Test. Quantitative data were summarized by the arithmetic mean and standard deviation. Comparison of means was done by One-Way Analysis of Variance (ANOVA). Pearson's correlation coefficient was also used to determine the degree and direction of the relationship between 4 quantitative variables.

\section{RESULTS:}

Table (1): indicates staff morale level among professional nurses. As indicated in the table and figure above half of professional nurses (51.4\%) had moderate level of staff morale, whereas nearly third of them (30.7\%) had low level of staff morale. Regarding personal perception of staff morale, above half of professional nurses (51.5\%) got low perception of staff morale. Moreover, 
$41.6 \%$ of professional nurses got moderate perception of staff morale, and only $9.6 \%$ of them got high perception of staff morale.In relation to negative factors affecting staff morale, above half of professional nurses $(59.4 \%)$ perceived moderate effect of negative factors affecting their morale, followed by above quarter of them (26.7\%) perceived low effect of negative factors affecting their morale, while only $13.9 \%$ of them perceived high effect of the same factors.

As for positive factors affecting staff morale, above half of professional nurses (56.4\%) perceived moderate effect of positive factors affecting their morale; moreover, $37.7 \%$ of professional nurses perceived high effect of positive factors affecting their morale, whereas only $5.9 \%$ of them perceived low effect of positive factors affecting their morale.

Table (2): shows level of intention to leave among professional nurses. As observed in the table and figure above half of professional nurses (52.5\%) had moderate level of intention to leave, followed by nearly one third $(30.7 \%)$ of professional nurses, who had low level of intension to leave, while only $16.8 \%$ of them had high level of intention to leave.

Table (3): show that there was significant negative correlation between intention to leave and personal perception of staff morale $(\mathrm{p}=0.026)$. While, there was positive significant correlation between intention to leave and negative factors affecting staff morale $(p=0.041)$.

Table (1): Staff morale level among professional nurses.

\begin{tabular}{|c|c|c|c|c|c|c|}
\hline \multirow{3}{*}{ Staff Morale } & \multicolumn{6}{|c|}{$\begin{array}{c}\text { Professional Nurses } \\
\qquad(\mathrm{N}=\mathbf{1 0 1})\end{array}$} \\
\hline & \multicolumn{2}{|c|}{ Low } & \multicolumn{2}{|c|}{ Moderate } & \multicolumn{2}{|c|}{ High } \\
\hline & No. & $\%$ & No. & $\%$ & No. & $\%$ \\
\hline $\begin{array}{l}\text { Personal perception of } \\
\text { staff morale }\end{array}$ & 52 & 51.5 & 42 & 41.6 & 7 & 6.9 \\
\hline $\begin{array}{l}\text { Negative factors } \\
\text { affecting staff morale }\end{array}$ & 27 & 26.7 & 60 & 59.4 & 14 & 13.9 \\
\hline $\begin{array}{l}\text { Positive factors affecting } \\
\text { staff morale }\end{array}$ & 6 & 5.9 & 57 & 56.4 & 38 & 37.7 \\
\hline Total staff morale & 31 & 30.7 & 52 & 51.4 & 18 & 17.9 \\
\hline
\end{tabular}

Low: Score $\%<33 \%$ Moderate: Score $\% 33 \%<66 \%$ High: Score $\% \geq 66 \%$ 
Table (2): Intention to leave among professional nurses.

\begin{tabular}{|c|c|c|}
\hline \multirow{2}{*}{ Intention to Leave } & \multicolumn{2}{|c|}{$\begin{array}{c}\text { Professional nurses } \\
(\mathbf{N}=101)\end{array}$} \\
\cline { 2 - 3 } & No. & $\%$ \\
\hline High & 17 & 16.8 \\
Moderate & 53 & 52.5 \\
Low & 31 & 30.7 \\
\hline
\end{tabular}

Low: Score $\%<33 \% \quad$ Moderate: Score $\% 33 \%<66 \%$ High: Score $\% \geq 66 \%$

Table (3): Relationship between staff morale and intention to leave among professional nurses.

\begin{tabular}{|ll|c|}
\hline \multicolumn{2}{|c|}{ Variables } & $\begin{array}{c}\text { Intention to } \\
\text { leave }\end{array}$ \\
\hline Personal perception of staff morale & Pearson Correlation & -0.222 \\
& Sig. & $0.026^{*}$ \\
\hline Negative factors affecting staff morale & Pearson Correlation & 0.204 \\
& Sig. & $0.041^{*}$ \\
\hline Positive factors affecting staff morale & Pearson Correlation & 0.086 \\
& Sig. & 0.395 \\
\hline Total Staff Morale & Pearson Correlation & 0.094 \\
& Sig. & 0.349 \\
\hline
\end{tabular}

* Significant correlation at $(\mathrm{p} \leq 0.05)$

\section{DISCUSSION:}

In reference to staff morale, the result of this study indicates that half of the professional nurses had moderate level of staff morale. And this is supported with Balcanoff (2013) who studied the effect of communication on hospital nursing morale and retention and found that the participants reported that poor communication between nurses in the hospital negatively affected morale. When nurses are overworked, stressed, or have other personal conflicts, communication between nurses is fragmented or poor. This can be frustrating for nurses, causing a low morale, but also can be detrimental to the patient.

In this regard, Dawson, Stasa, Roche, Homer, \& Duffield, (2014) who studied nursing churn and turnover in Australian hospitals: nurses perceptions and suggestions for supportive 
strategies and found that key factors affecting nursing low staff morale were limited career opportunities; poor support; a lack of recognition; and negative staff attitudes. The nursing working environment is characterized by inappropriate skill-mix and inadequate patient-staff ratios, a lack of qualified nurses with appropriate skills, and increased patient demands. These issues impacted upon heavy workloads and stress levels with nurses feeling undervalued, disempowered and low staff morale.

As for intention to leave, the results of this study show that above half of professional nurses had moderate level of intention to leave and this may attributed to Professional nurses are still stable in their job, feel comfortable within the work, modified with the hospital's policies, having supervisory support and or probably because of the difficulty in finding alternative employment or fitting into a new workplace and demand to the work. This result was supported by leone et al. (2015) who studied work environment issues and intention-to-leave in Portuguese nurses: A study suggested that improving nurse' perceptions of opportunities for professional advancement and growth could be the most important strategy to improve retention and job satisfaction among professional nurses.

Moreover, Lutter (2011) who studied an exploration of registered nurses' intentions to leave the profession and proved that increased perceptions of job stress, the inability to provide safe and ethical care, conflicts between work and family life, few opportunities for career advancement and professional development, few opportunities to participate in decision-making, and inadequate financial compensation have all been found to contribute to higher intentions to leave the nursing profession. Furthermore, quality of teamwork and supervisory support were also found to be major factors in preventing workplace violence and intention to leave (Estryn-Behar et al., 2008).

This result consistent with Vincent (2016) suggested that managers reported moderate intention to leave their organization. Moreover, Hassan (2013) who studied the relationship among professional nurses' leadership style, organizational commitment and intention to leave and revealed that highly statistical significant deference in terms of the intent to leave between first line nurse managers and professional nurses. In addition to that, Palumbo, Rambur, McIntosh, \& Naud, (2010) who studied registered nurses' perceptions of health and safety related to their intention to leave and illustrated that intention to leave is lower in those nurses who perceive better emotional health and more attention paid to safety and health initiatives. 
In regarding to correlation between staff morale and intention to leave, there was significant negative correlation between personal perception of staff morale and intention to leave. This result may be related to professional nurses feeling valued by the organization, good communication between health care team, feel pride in their profession, sharing in decision making, and there were a lot of job enthusiasm in this hospital, they don't think to leave the hospital . This result was supported by Behm (2009), Martini (2010), Travis \& Mor Barak (2010) Avery, McKay, Wilson, Volpone, \& Killham, (2011) who concluded that when employees express their views and concerns with no repercussions, there are favorable organizational outcomes, including trust for the organization, motivation, and reduced turnover, and increased morale.

Moreover, Stress associated with training nurses or working with untrained nurses can cause low morale and decreased group productivity (Jones, 2008). Furthermore, Beck (2005), Evans \& Kaye (2003), \& Rice (2005) shown that many factors influence employee retention and morale; these include effective communication, employee recognition and an environment that inspires learning, creativity, innovation, flexibility and learning.

This result was consistent with Balcanoff (2013) found that there was relationship between staff morale and intention to leave. Furthermore, Hayes, Bonner, \& Pryor (2010) who studied factors contributing to nurse job satisfaction in the acute hospital setting and suggested that low morale influences nurse turnover. Moreover, Harrison, Lambiase, \& Zhao (2010) who studied organizational factors associated with quality of care in US teaching hospitals and proved that loss of morale leads to a lack of nurse commitment to the organization, which contributes to nurse turnover. Furthermore, Cottingham et al. (2011) who studied partners in nursing: a mentoring initiative to enhance nurse retention and found that low morale financially affects hospitals and increases the risk of nurse turnover. In addition to that Behm (2009) indicated that employee turnover is expensive for the organization and negatively affects morale.

The findings of the present study indicated that there was positive significant correlation between intention to leave and negative factors affecting staff morale. This result may be attributed to increase work load, decrease availability of in service staff development program, lack of clear communication, poor public and media image of staff nursing, and conflict between administration lead to increase intention to leave. This result was supported by Douglas (2010), Parker, Giles \& Higgins (2009) who studied taking action to close the nursing-finance gap: 
learning from success and found that there was several issues negatively affect morale: conflict between administration and nursing, ineffective communication, absenteeism, retention and recruitment, staff turnover, and health risks.

Moreover, the distrust of management, poor interpersonal relations (i.e., relationships between leader and staff), and inflexible working conditions could be other factors that affect staff morale (Dye \& Garman, 2006). According to Workforce Performance Solutions (2006), low morale may be caused by departmental layoffs or closures, labor negotiations and contract disputes, high employee turnover rates, changes in leadership, and unclear expectations. They also stated that the lack of opportunity for personal growth because of unchallenging environments leads to low morale.

This result was at the same line with Dyo, Kalowes, \& Devries (2016) who studied moral distress and intention to leave: A comparison of adult and pediatric nurses by hospital setting and suggested that moral distress frequency showed a positive relationship with intention to leave a position of employment. Moreover, Allen et al. (2013) who studied moral distress among healthcare professionals at a healthcare system and found that moral distress was significantly higher among individuals who had actually left or were contemplating leaving a position compared to those who had no intention of leaving.

\section{CONCLUSION:}

The findings from this study concluded that professional nurses had moderate level of staff morale and intention to leave. Moreover, there was significant negative relationship between intention to leave and personal perception of staff morale. While, there was positive significant relationship between intention to leave and negative factors affecting staff morale.

\section{RECOMMENDATIONS:}

\section{Based on the findings of the present study, the following recommendations are suggested to different administrators' level; as well as to professional nurses.}

\section{A. Healthcare organization administrators should:}

1. Increase professional nurses' satisfaction through competitive salaries, encourage the team work spirit and conduct periodical meetings to discuss their problems.

2. Conduct frequent meetings with professional nurses who are dissatisfied from their job; discuss their problems and their needs and try to formulate plans to overcome these problems to enhance 
their satisfaction level which can consequently raise their morale and commitment level and decrease level of intention to leave.

\section{B. For professional nurses}

1. Attend in- service education programs concerning topics, such as: communication strategies, self awareness, career development opportunities, time management, problem solving, decision making, mentoring and coaching

2. Discuss their problems and their needs with the administrators to overcome these problems to enhance their satisfaction level which can consequently raise their organizational commitment level.

3. Able to identify their believes, values, hopes, interest and needs and knowing to what extent it match with the hospital values, believes and goals.

\section{REFERENCES:}

Aiken, L. (2010). Safety in numbers. Nursing Standard, 24(44): 62-63.

Allen, R., Judkins-Cohn, T., Velasco, R., Forges, E., Lee, R., \& Clark, L. (2013). Moral distress among healthcare professionals at a healthcare system. Journal Nursing Administration Healthcare Law Ethics Regulations, 15 (3): 111-118. Available at: http://www.nursingcenter.com/cearticle?an=00128488201307000-

00003\&Journal_ID=260876\&Issue_ID=1589160. Retrieved on: 20/4/2017.

Avery, R., McKay, F., Wilson, C., Volpone, D., \& Killham, E. A. (2011). Does voice go flat? How tenure diminishes the impact of voice. Human Resource Management, 50: 147-158.

Balcanoff, K. (2013). The Effect of Communication on Hospital Nursing Morale and Retention. (Doctoral thesis, College of Management and Theory, Walden University, Minnesota). Available at: http://search.proquest.com.ugrade1.eul.edu.eg:2048/pqdtglobal/docview/1288420375/44C E03F388FE4187PQ/1? accountid=37552. Retrieved on: 15/4/2015.

Beck, M. (2005). Exceptional leadership inspires the best efforts in others. Available at: http://www.barrelpublishing.com/articles/exceptional leadership inspires the best effort in others, shtml. Retrieved on: 20/4/2017. 
Behm, M. (2009). Employee morale. Professional Safety, 54(10): 42-49.

Brennan, C., \& Daly, B. (2009). Patient acuity: A concept analysis. Journal of Advanced Nursing: 65(5), 1114-1126.

Chaaban, A. (2006). Job satisfaction, organizational commitment and turnover intent among nurse anesthetists in Michigan. Dissertation Abstracts International, 67(01).

Christmas, K. (2008). How work environment impacts retention. Nursing Economics, 26: 316318. Available at: http://www.nursingeconomics.net. Retrieved on: 28/2/2017.

Cottingham, S., DiBartolo, M., Battistoni, S., \& Brown, T. (2011). Partners in nursing: A mentoring initiative to enhance nurse retention. Nursing Education Perspectives, 32: 250255.

Dawson, A., Stasa, H., Roche, M., Homer, C., \& Duffield, C. (2014). Nursing churn and turnover in Australian hospitals: nurses perceptions and suggestions for supportive strategies. Available at: https://bmcnurs.biomedcentral.com/articles/10.1186/1472-6955-13-11. Retrieved on: 15/4/2017.

Day, E., Minichiello, V., \& Madison, J. (2006). Nursing morale: what does the literature reveal? Australian Health Review, 30(4): 516-524.

Denka, A. (2009). Boosting employee morale: Luxury or bottom-line concern in today's economy? Corporate Finance Review, 14(2): 16-19.

Douglas, K. (2010). Taking action to close the nursing-finance gap: Learning from success. Nursing Economics, 28: 270-272. Available at: http://www.nursingeconomics.net. Retrieved on: 28/2/2017.

Dye, C. \& Garman, A. (2006). Exceptional Leadership: 16 Critical Competencies for Healthcare Executives. Chicago: Health Administration Press.

Dyo, E., Kalowes, P., \& Jessica Devries, J. (2016). Moral distress and intention to leave: A comparison of adult and pediatric nurses by hospital setting. Intensive and Critical Care Nursing, (36): 42-48. 
Ellenbecker, H. (2004). A theoretical model of job retention for home health care nurses. Journal of Advanced Nursing, 47, 303-310.

Estryn-Behar, M., van der Heijden, B., Camerino, D., Fry, C., Le Nezet, O., \& Conway, P. M. (2008). Violence risks in nursing: Results from the European 'NEXT' Study. Occupational Medicine, 58(2): 107-114.

Evans, S. \& Kaye, B. (2003). How to retain high-performance employees. Available at: http://www.careersvstemsintl.com/PDF\%20Files/How\%20to\%20Retain\%20HighP erformance\%20Emplo yees .pdf. Retrieved on: 20/4/2017.

Flinkman, M., Leino-Kilpi, H., \& Salantera, S. (2010). Nurses ${ }^{e e}$ intention to leave the profession: Integrative review. Journal of Advanced Nursing, 66: 1422-1434.

Harrison, P., Lambiase, R., \& Zhao, M. (2010). Organizational factors associated with quality of care in US teaching hospitals. Journal of Health Care Finance, 36(3): 1-12.

Hassan, H. (2013). The relationship among professional nurses' leadership style, organizational commitment and intention to leave (Unpublished Master Thesis,Faculty of Nursing, Alexandria University, Egypt).

Hayes, B., Bonner, N., \& Pryor, J. (2010). Factors contributing to nurse job satisfaction in the acute hospital setting: A review of recent literature. Journal of Nursing Management, 18: 804-814.

Jones, B. (2008). Revisiting nurse turnover costs: Adjusting for inflation. Journal of Nursing Administration, 38: 11-18.

Kim, W., Price, L., Mueller, W. \& Watson, W. (1996). The determinants of career intent among physicians at a U.S. Air Force hospital. Human Relations49 (1): 947.

Kocakülâh, C., Wiggins, M., \& Albin, M. (2009). Managing manpower and cutting costs in the health care industry. Journal of Health Care Finance, 35(3): 80-92. Available at: http://www.aspenpublishers.com. Retrieved on: 28/2/2017.

Leonea, C., Bruyneel L., Andersona, J., Murrells T., Dussault G., Jesus É., Sermeus, W., Aikene, L., \& Raffertya, A. (2015). Work environment issues and intention-to-leave in Portuguese 
nurses: A cross-sectional study. Health Policy, 119 (12): 15841592.Availableat:http://www.sciencedirect.com.ugrade1.eul.edu.eg:2048/science/article/pi i/S0168851015002432. Retrieved on: 19/4/2017.

Long, S., \& Spurlock, G. (2008). Motivation and stakeholder acceptance in technology-driven change management: Implications for the engineering manager. Engineering Management Journal, 20(2): 30-36.

Lutter, S. (2011). An exploration of registered nurses' intentions to leave the profession. (Doctoral thesis, College of Behavioral Sciences and Education, Pennsylvania University, Pennsylvania).

Availableat:http://search.proquest.com.ugrade1.eul.edu.eg:2048/pqdtglobal/docview/8877 09426/6ACA66B4088342C8PQ/1? accountid=37552. Retrieved on: 19/4/2017.

Mapesa N. (2014) an Inquiry into the Impact of Internal Communication on Hospital Nursing Staff Morale. (Master thesis, faculty of Commerce, Bindura University of Science Education, Zimbabwe).

Martini, M. (2010). Communication an important management task in the hospital market. Journal of Management and Marketing in Healthcare, 3(1): 9-12.

McKenna, E., Clement, K., Thompson, E., Haas, K., Weber, W., Wallace, M., \& Roda, I. (2011). Using a nursing productivity committee to achieve cost savings and improve staffing levels and staff satisfaction. Critical Care Nurse, 31(6): 55-65.

Palumbo, M., Rambur,R., McIntosh, B., \& Naud, S. (2010). Registered Nurses' Perceptions of health and safety related to their Intention to Leave. American Association of Occupational Health Nurses. 58 (3): 95-103.

Parker, V., Giles, M., \& Higgins, I. (2009). Challenges confronting clinicians in acute care. Journal of Nursing Management, 17: 667-678.

Rice, E. (2005). The evolving role o $\mathrm{f}$ the $\mathrm{hr}$ executive. Available at:http://www.innovativeemploveesolutions.com/knowledge/articles 04/article45strategicHR.html. Retrieved on: 20/4/2017. 
Swiadek, J. (2009). The impact of healthcare issues on the future of the nursing profession: The resulting increased influence of community-based and public health nursing. Nursing Forum, 44: 19-24.

Takase, M. (2010). A concept analysis of turnover intention: Implications for nursing management. Collegian, 17: 3-12.

Travis, D., \& Mor Barak, M. (2010). Fight or flight? Factors influencing child welfare workers' propensity to seek positive change or disengage from their jobs. Journal of Social Service Research, 36: 188-205.

Unruh, L. (2008). Nurse staffing and patient, nurse, and financial outcomes. The American Journal of Nursing, 108(1): 62-71.

Vincent, D. (2016). Commitment to Social Justice and its Influence on Job Satisfaction and Retention of Nonprofit Middle Managers. (Doctoral thesis, Graduate School of Social Services, Fordham University, New York). Available at: http://search.proquest.com.ugrade1.eul.edu.eg:2048/pqdtglobal/docview/1836064837/9B7 3D26794624C9EPQ/1 ?accountid=37552. Retrieved on: 15/4/2015.

Weeb, H. (2003). Testing of an Intervention to Decrease Certified Nursing Assistant (CAN) Turnover in A Nursing Home. (Doctoral thesis, UNIVERSITY OF RHODE ISLAND, USA). Available at: http://digitalcommons.uri.edu/dissertations/AAI3115642/. Retrieved on: $13 / 7 / 2017$.

Workforce Performance Solutions. (2006). The high cost of low morale. Available at: http://www.wpsmag.com. Retrieved on: 15/4/2017. 


\section{العلاقة بين الروح المعنوية والعزم على ترك المهنة بين أخصائيات التمريض}

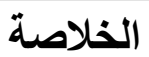

الاحتفاظ بهيئة التمريض في المستشفى مهم لسلامة وصحة المرضى. أظهرت الدر اسات أن نسب المررضات إلى المرضى هي متغيرات مهمة تؤثر على صحة المرضى. الإحتفاظ بالممرضات هو مسألة معقدة تواجه

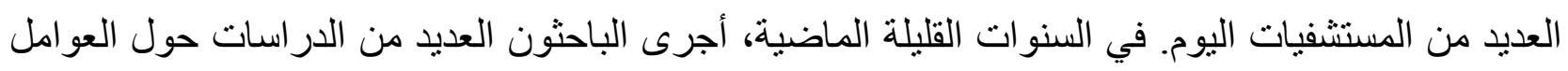
المحتملة المتعلقة بالعزم على نرك العمل ووجد أنه يوجد العديد من العو امل. من ضمن تلك العوامل الرضا الوظيفى، الروح المعنوية، مكان العمل، التحكم فى المهارات التمريضية، المرتبات، الاستقلالية، التركيز على الخبرة، الإعتراف بالعمل المنجز، العلاقة مع الزملاء، العلاقة مع الع

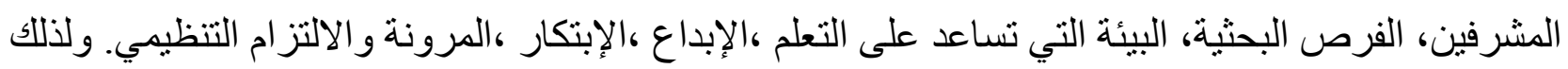

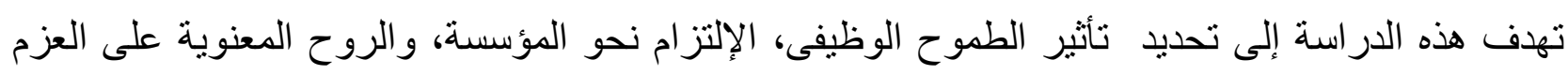
على ترك المهنة بين أخصائيات التمريض. 